\title{
Intraoperative lavage cytologic analysis of surgical margins in patients undergoing limited surgery for lung cancer
}

Masahiko Higashiyama, MD, ${ }^{a}$ Ken Kodama, MD, ${ }^{a}$ Koji Takami, MD, ${ }^{a}$ Naozumi Higaki, MD, ${ }^{a}$ Tomio Nakayama, MD, ${ }^{\text {b }}$ and Hideoki Yokouchi, MD

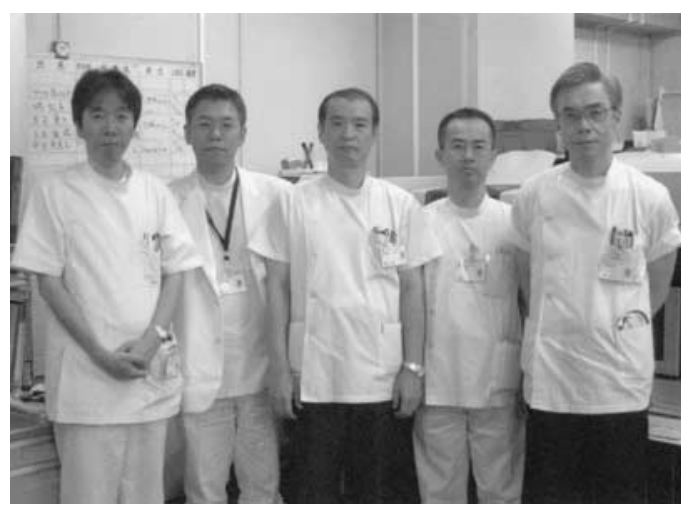

Higaki, Nakayama, Higashiyama, Takami, Kodama (left to right)
Background: One of the unfavorable recurrent patterns after limited surgery for lung cancer is local failure, especially at the surgical margin in the pulmonary parenchyma. To prevent this failure, we preliminarily introduced a novel intraoperative lavage cytologic technique to check surgical margin status for limited surgery. In this study we analyzed the clinical utility of this technique with a larger number of patients under long-term follow-up.

Methods: A total 112 consecutive lung cancer lesions prospectively treated by limited surgery with the intraoperative lavage cytologic technique between October 1997 and August 2000 were reviewed through a median follow-up period of 27 months.

Results: Eleven lesions (10\%) showed cytologically positive results in the attempted surgery on the surgical margin. The positive result rate was significantly higher for lesions with more advanced stage, compromised indication, incurability, and larger size. Surgical modes were converted intraoperatively for 4 lesions; in the other 7 lesions no conversion was performed because of certain disadvantages. Local recurrence in the surgical margin occurred in a total of 4 lesions, including 3 for which the operative mode was unconverted and 1 lesion with cytologically unknown status of the surgical margin that had the mode converted, whereas there were no local recurrences in the surgical margins among the lesions with final cytologically negative results.

From the Departments of Thoracic Surgery $^{\mathrm{a}}$ and Respiratory Medicine, ${ }^{\mathrm{b}}$ Osaka Medical Center for Cancer and Cardiovascular Diseases, and the Department of Surgery, ${ }^{\mathrm{c}}$ Suita Municipal Hospital, Osaka, Japan.

Supported in part by Grant-in-Aid for Cancer Research 13-9 from the Ministry of Health, Labor, and Welfare of Japan.

Received for publication Dec 18, 2001; revisions requested March 8, 2002; revisions received July 2, 2002; accepted for publication July 15, 2002.

Address for reprints: Masahiko Higashiyama, MD, Department of Thoracic Surgery, Osaka Medical Center for Cancer and Cardiovascular Diseases, Nakamichi 1-3-3, Higashinari-ku, Osaka, 537-8511, Japan (E-mail: higamasa@rj8.so-net.ne.jp or higasiyama-ma@mc.pref.osaka.jp).

J Thorac Cardiovasc Surg 2003;125:101-7

Copyright $\odot 2003$ by The American Association for Thoracic Surgery

$0022-5223 / 2003 \$ 30.00+0$

doi: $10.1067 / \mathrm{mtc} .2003 .92$
Conclusion: Cytologically negative results of examination of the surgical margin by the technique of intraoperative lavage cytologic in limited surgery for lung cancer may be predict lack of local recurrence in the surgical margin. This intraoperative cytologic technique is clinically useful in checking for complete resection of this primary disease.

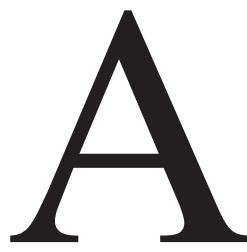

lthough limited surgical procedures, such as segmentectomy, wide wedge resection (WWR) under open thoracotomy, and video-assisted thoracic surgery (VATS), have been more aggressively performed for small lung carcinoma, the risk for the tumor residue in the pulmonary parenchyma of the surgical margin is greater. $^{1-8}$ In particular, when a tumor is very small (usually less than $10 \mathrm{~mm}$ in diameter), a well-differentiated adenocarcinoma such as a bronchioloalveolar type, type IV on Higashiyama's classification, ${ }^{9}$ or the deep-seated type within the pulmonary parenchyma beneath the pleura, its margin is often undetermined during the operation.

To avoid this unfortunate local failure, we developed a novel checking test, intraoperative lavage cytologic examination of the surgical margin, for limited 


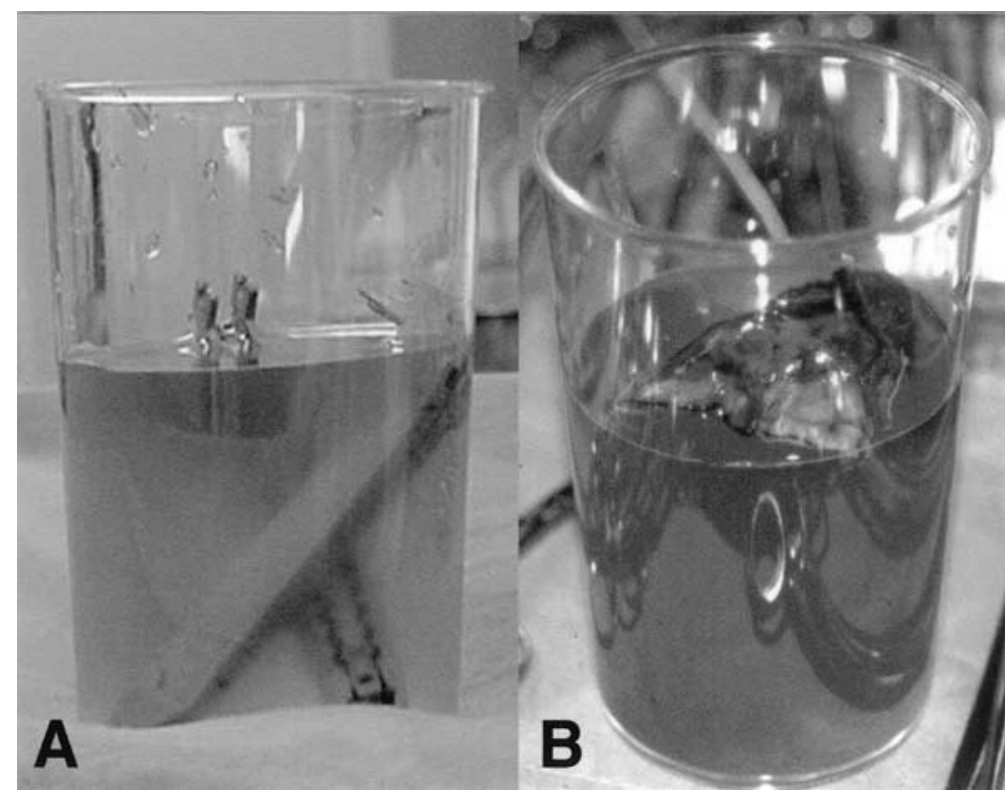

Figure 1. Lavage cytologic technique of surgical margin in limited surgery for lung cancer. A, When limited surgery was performed with stapler, its fired cartridges were collectively washed in saline solution for lavage cytologic examination. B, When limited surgery was performed with Nd:YAG laser or electric scissors, alone or in combination with stapler, specimen was washed without flooding of pleural surface in saline solution for lavage cytologic examination.

surgery. ${ }^{10}$ Moreover, we recently reported that this checking system is potentially useful to obtain complete local cure in metastasectomy for pulmonary metastases. ${ }^{11}$

On the basis of our preliminary results, ${ }^{10}$ we prospectively used this technique in limited surgery for lung cancer. In this study, with a large number of patients under longterm follow-up, we reviewed the clinical utility of this technique as a predictor of local completeness in the surgical margin.

\section{Patients and Methods}

Between October 1997 and August 2000, limited surgery was preoperatively scheduled for 110 consecutive patients with primary lung cancer comprising a total of 115 lesions in our institute on the basis of the following two indications: intentional and compromised cases. The former group, in which 60 lesions were included, underwent limited surgery under the selected criterion of peripheral small-sized clinical-stage IA lung cancer, as described previously by Kodama and colleagues. ${ }^{1,4}$ Most patients whose lesions were $20 \mathrm{~mm}$ or smaller and type III and IV adenocarcinoma according to Higashiyama and associates' classification ${ }^{9}$ were aggressively entered into this group. The latter group, in which 55 lesions were included, principally underwent limited resection because of preoperative high-risk complications, multiple lung cancers, or advanced age. Of the lesions in this study, 59 lesions resected between October 1997 and March 1999 were registered in our preliminary report. ${ }^{10}$ With regard to the clinical stage of the latter group, 39 lesions were of stage IA, 9 were of stage IB, 2 were of stage IIB, 3 were of stage IIIA, 1 was of stage
IIIB, and 1 was of stage IV because of brain metastasis. For 110 lesions limited surgery was attempted through thoracotomy, whereas 5 lesions were resected with VATS. However, conversion to standard surgery for lung cancer was performed in 3 lesions of intentional indication because regional lymph node involvement was detected during the operation. Therefore, excluding the previously mentioned 3 lesions in 3 patients, a total of 112 lesions in 107 patients with 57 intentional and 55 compromised indications were analyzed in this study.

The patients, aged 34 to 84 years (mean 63.0 years), included 59 men and 48 women. Tumor size ranged from 0.5 to $5.5 \mathrm{~cm}$ (median size $1.6 \mathrm{~cm}$ ). Thirty-five lesions were $1 \mathrm{~cm}$ or smaller, 36 were between $1.1 \mathrm{~cm}$ and $2.0 \mathrm{~cm}, 28$ were between $2.1 \mathrm{~cm}$ and 3.0 $\mathrm{cm}$, and 13 were larger than $3.0 \mathrm{~cm}$. Histologically, only 37 lesions were preoperatively diagnosed as lung cancer. Finally, 91 lesions were adenocarcinomas, 14 were squamous cell carcinomas, 4 were large cell carcinomas, and 3 were other histologic types (2 small cell lung cancers and 1 adenosquamous cell carcinoma).

The operative techniques of WWR $(n=55)$, VATS-WWR $(\mathrm{n}=5)$, and segmentectomy $(\mathrm{n}=52)$ have been previously described elsewhere. ${ }^{1,4,8,12} \mathrm{We}$ designated the method of wedge resection with macroscopically greater safe margin than the tumor diameter as WWR. ${ }^{8}$ Stapler, Nd:YAG laser, and electric scissors were used to divide the pulmonary parenchyma with such a safe margin. Pleural lavage cytologic examination was performed immediately after thoracotomy to avoid tumor cell contamination on the surgical margin in 97 lesions ${ }^{13}$ but was not done in the other 15 lesions because of severe pleural adhesion.

The lavage cytologic technique for the surgical margin, as described previously, is as follows. ${ }^{10}$ Briefly, when limited surgery 


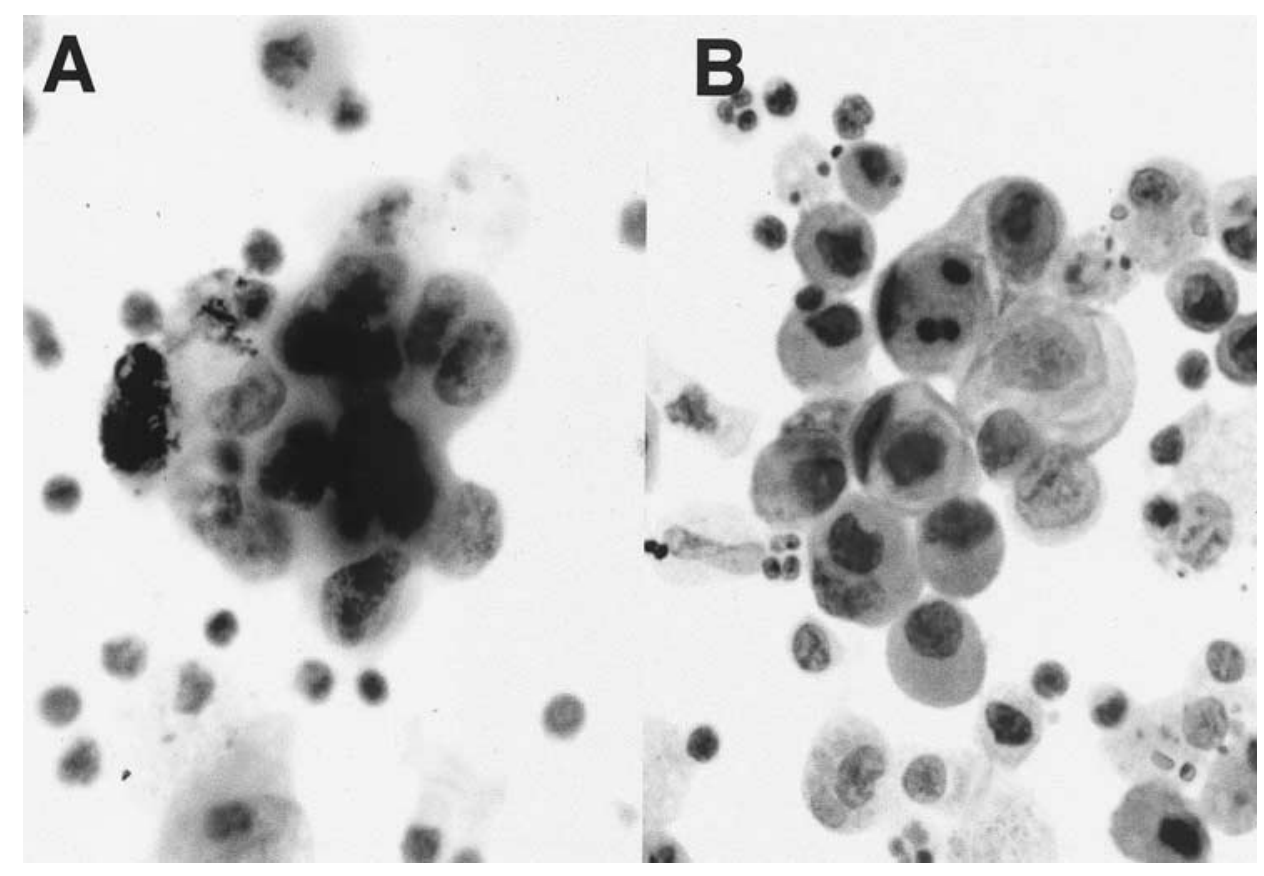

Figure 2. Representative cytologically positive specimens by lavage cytologic technique of surgical margin in limited surgery for lung cancer. A, Adenocarcinoma. B, Squamous cell carcinoma.

was performed with a stapler alone, all fired cartridges were washed in $200 \mathrm{~mL}$ saline solution (Figure 1, A). When tumor excision was performed with the Nd:YAG laser, electric scissors, or a combination with a stapler, the resected specimens were similarly washed without flooding of the pleural surface (Figure 1, $B)$. When tumors were resected with combined methods, both the used cartridges and the resected samples were washed. These lavage techniques were carefully performed with the avoidance of tumor cell contamination from the pleural surface and were also done before making cross-sections of the specimens.

After centrifugation, the sediment was immediately fixed with Saccomanno solution and was then smeared on a glass slide by Cytospin (Thermo Electron Corporation, Waltham, Mass). Then, after final refixation with ethanol and diethyl ether, the sediment was stained with the Papanicolaou method. The cytologic results were judged as positive (Figure 2) or negative by a cytologist and were then immediately reported to the operating room. It usually took approximately 15 to 25 minutes for the completion of these lavage cytologic examinations.

A total of 7 lesions showed incurability at the end of the operation because of conventionally unfavorable findings as follows: tumor residue in the lymph nodes in 2 lesions, tumor residue because of multiple lung cancer in 3 lesions, pleural dissemination in 1 lesion, and brain metastasis in 1 lesion.

To check the surgical margin status in the enrolled lesions undergoing limited surgery, postoperative follow-up examinations were principally performed by plain chest roentgenography every 3 to 6 months and by computed tomographic scan every 6 to 12 months. Local recurrence in the surgical margin was diagnosed by clinical course and laboratory data, especially focusing on abnormal growing or regrowing shadows on computed tomographic scan in the surgical margin area, namely involving the stapler line within the pulmonary parenchyma. The median follow-up period of the patients was 27 months, ranging from 5 to 47 months. Counts were compared with the Fisher exact test.

\section{Results}

\section{Association Between Positive Cytologic Result and Clinicopathologic Factors in the Attempted Limited Surgery}

Of the lesions examined in this series, 11 lesions (10\%) in 10 patients showed cytologically positive results (Figure 2) in the surgical margin despite a macroscopically safe margin in the attempted limited surgery. Table 1 shows a summary of the association between positive cytologic results and clinicopathologic factors. The positive result rate was significantly associated with clinical stage, indication, pathologic stage, and curability and was marginally significantly associated with tumor size. Its rate was higher for lesions of more advanced clinical stage (clinical stage IB, II, III, and IV vs clinical stage IA $P=.002$ ) and pathologic stage (pathologic stage IB, II, III, and IV vs pathologic stage IA $P<.001$ ), those with compromised indications (compromised vs intentional $P=.003$ ), incurability (noncurative vs curative $P<.001)$, and larger tumor size $(>2.0 \mathrm{~cm}$ vs $\leq 2.0 \mathrm{~cm} P=.050$ ). There was no association between positive cytologic result and surgical method, dividing technique, or histologic type. 
TABLE 1. Summary of positive cytologic results and clinicopathologic factors

\begin{tabular}{|c|c|c|c|}
\hline & \multirow[b]{2}{*}{ Tested lesions (No.) } & \multicolumn{2}{|c|}{$\begin{array}{l}\text { Positive } \\
\text { results }\end{array}$} \\
\hline & & No. & $\%$ \\
\hline Total & 112 & 11 & 10 \\
\hline \multicolumn{4}{|l|}{ Tumor size $(\mathrm{mm})^{*}$} \\
\hline$\leq 1.0$ & 35 & 1 & 3 \\
\hline $1.1-2.0$ & 36 & 3 & 8 \\
\hline $2.1-3.0$ & 28 & 4 & 14 \\
\hline$\geq 3.1$ & 13 & 3 & 23 \\
\hline \multicolumn{4}{|l|}{ Clinical stage $†$} \\
\hline $\mathrm{IA}$ & 96 & 6 & 6 \\
\hline IB & 9 & 3 & 33 \\
\hline II, III, IV & 7 & 2 & 29 \\
\hline \multicolumn{4}{|l|}{ Indicationt } \\
\hline Intentional & 57 & 1 & 2 \\
\hline Compromised & 55 & 10 & 18 \\
\hline \multicolumn{4}{|l|}{ Attempted surgery } \\
\hline WWR & 55 & 8 & 15 \\
\hline VATS-WWR & 5 & 0 & 0 \\
\hline Segmentectomy & 52 & 3 & 6 \\
\hline \multicolumn{4}{|l|}{ Cutting technique } \\
\hline Stapler & 54 & 6 & 11 \\
\hline Nd: YAG laser & 24 & 3 & 13 \\
\hline Electric & 9 & 0 & 0 \\
\hline scissors & & & \\
\hline Combination & 25 & 2 & 8 \\
\hline \multicolumn{4}{|l|}{ Pathologic stage } \\
\hline IA & 93 & 4 & 4 \\
\hline IB & 15 & 5 & 33 \\
\hline II, III, IV & 4 & 2 & 50 \\
\hline \multicolumn{4}{|l|}{ Curability† } \\
\hline Curative & 105 & 7 & 7 \\
\hline Noncurative & 7 & 4 & 57 \\
\hline \multicolumn{4}{|l|}{ Histologic type } \\
\hline Adenocarcinoma & 91 & 7 & 8 \\
\hline Nonadenocarcinoma & 21 & 4 & 19 \\
\hline
\end{tabular}

*Marginally significant.

tSignificant.

\section{Intraoperative Conversion of Surgical Mode for}

Lesions with Cytologically Positive Results (Table 2)

For 4 lesions with cytologically positive results, intraoperative conversion of the surgical mode was performed. For 1 lesion with intentional indication (lesion 1), completion lower lobe lobectomy was immediately performed. Completion middle lobe lobectomy was carefully done for 1 lesion with compromised indication because of low respiratory function resulting from a severe tuberculosis scar (lesion 2). Completion segmentectomy was additionally performed for 1 lesion (lesion 3) undergoing WWR, and a cytologically negative result in the new margin area was finally obtained. Additional evaporation with the Nd:YAG laser on the surgical margin was narrowly done for 1 lesion (lesion 4) undergoing segmentectomy because of a compromised indication related to severely poor respiratory func- tion, but the final cytologic status of the new margin remained undetermined. On the other hand, no additional resection was performed for the other 7 lesions with positive results because of compromised indications related to cardiopulmonary disease in 1 lesion (lesion 5), tumor burden status of another organ origin in 1 lesion (lesion 6), multiple lung cancer in 3 lesions (lesions 7-9), and noncurative reasons in 2 lesions (lesions 10 and 11).

\section{Final Surgical Mode and Postoperative Results in the Surgical Margin}

Of the enrolled lesions, 2 (lesions 1 and 2) were finally resected by completion lobectomy, and in addition 1 lesion, despite a cytologically negative result in the margin, was also consequently resected by completion lobectomy because of an incidental benign lesion within the same lobe. Thus 109 lesions were resected by limited surgical mode, including 101 lesions with final cytologically negative results, 7 lesions left with cytologically positive results (lesions 5-11), and 1 lesion with final cytologic status undetermined (lesion 4).

During the follow-up period, local recurrence in the surgical margin occurred in a total of 4 lesions, including 3 cytologically positive lesions for which the mode was unconverted (lesions 8-10) and 1 lesion that was cytologically undetermined after further evaporation (lesion 4). Despite intraoperative Nd:YAG laser evaporation treatment against the cytologically positive surgical margin, the lesion 4 recurred in this area 25 months after the operation. The patient with lesion 7 died of bone metastases with no evidence of local recurrence in the surgical margin 13 months after the operation. The follow-up data for the patient with lesion 10 were lost 5 months after the operation because the patient moved away. In contrast, there were no local recurrences in the surgical margin area among the patients with cytologically negative results. These results are summarized in Figure 3.

\section{Discussion}

Along with the recent dramatic increase in relatively smaller sized lung cancer or early lung cancer with clinical staging of T1 N0,1,4,6-9,14 there has been more opportunity for limited surgery for this disease with not only compromised but also intentional indications. In prospectively attempting this surgical mode, however, stricter intraoperative evaluation of the following two problems of local curability may be required: nodal metastasis and complete resection of the primary lesion. To overcome the former problem, node dissection or sampling should be selectively and carefully performed. ${ }^{1,4,6,7}$ On the other hand, a checking test for local completeness of the primary lesion has not been practically satisfactory.

Usually, limited surgery should be performed while maintaining a macroscopically safe surgical margin. In our 
TABLE 2. Intraoperative conversion of surgical mode for lung cancer lesions with cytologically positive results

\begin{tabular}{|c|c|c|c|c|c|c|c|c|c|}
\hline $\begin{array}{l}\text { Lesion } \\
\text { No. }\end{array}$ & Disease & $\begin{array}{l}\text { Clinical } \\
\text { stage }\end{array}$ & $\begin{array}{l}\text { Tumor } \\
\text { size } \\
(\mathrm{mm})\end{array}$ & Indication & $\begin{array}{l}\text { Attempted surgery } \\
\text { and cutting } \\
\text { technique }\end{array}$ & Conversion & $\begin{array}{c}\text { Pathologic } \\
\text { stage }\end{array}$ & Follow-up & $\begin{array}{c}\text { Recurrence } \\
\text { in surgical } \\
\text { margin }\end{array}$ \\
\hline 2 & $\begin{array}{l}\text { Squamous } \\
\text { cell } \\
\text { carcinoma }\end{array}$ & T2 No & 34 & Compromised & WWR, stapler & $\begin{array}{l}\text { Completion } \\
\text { lobectomy }\end{array}$ & T2 No & $\begin{array}{l}\text { Alive without return } \\
\text { or recurrence, } 18 \\
\text { mo }\end{array}$ & \\
\hline 3 & $\begin{array}{l}\text { Adeno- } \\
\text { carcinoma }\end{array}$ & T1 N0 & 20 & Compromised & WWR, stapler & $\begin{array}{l}\text { Completion } \\
\text { segmentectomy }\end{array}$ & T1 No & $\begin{array}{l}\text { Alive without return } \\
\text { or recurrence, } 16 \\
\text { mo }\end{array}$ & No \\
\hline 4 & $\begin{array}{l}\text { Adeno- } \\
\text { carcinoma }\end{array}$ & T1 N0 & 28 & Compromised & $\begin{array}{c}\text { Segmentectomy, } \\
\text { Nd:YAG laser }\end{array}$ & $\begin{array}{l}\text { Additional } \\
\text { evaporation }\end{array}$ & T1 N0 & $\begin{array}{l}\text { Alive with tumor } \\
\text { recurrence, } 28 \\
\text { mo }\end{array}$ & Yes \\
\hline 6 & $\begin{array}{l}\text { Large cell } \\
\text { carcinoma }\end{array}$ & T2 N2 & 22 & Compromised & $\begin{array}{l}\text { Segmentectomy, } \\
\text { stapler }\end{array}$ & $\begin{array}{l}\text { No (tumor-burden } \\
\text { status) }\end{array}$ & T2 N0 P2 & $\begin{array}{l}\text { Alive without return } \\
\text { or recurrence, } 42 \\
\text { mo }\end{array}$ & No \\
\hline 7 & $\begin{array}{l}\text { Adeno- } \\
\text { carcinoma }\end{array}$ & T1 N0 & 25 & Compromised & $\begin{array}{l}\text { Segmentectomy, } \\
\text { stapler plus } \\
\text { Nd:YAG laser }\end{array}$ & $\begin{array}{l}\text { No (multiple lung } \\
\text { cancers, } \\
\text { noncurative) }\end{array}$ & T2 N0 & Death, 13 mo & No \\
\hline 8,9 & $\begin{array}{l}\text { Adeno- } \\
\text { carcinoma }\end{array}$ & $\begin{array}{l}\text { T2 N0, } \\
\text { T1 No }\end{array}$ & $\begin{array}{l}40 \\
10\end{array}$ & Compromised & $\begin{array}{l}\text { WWR, WWR, } \\
\text { Nd:YAG laser, } \\
\text { stapler plus } \\
\text { Nd:YAG laser }\end{array}$ & $\begin{array}{l}\text { No (multiple lung } \\
\text { cancers, } \\
\text { noncurative) }\end{array}$ & $\begin{array}{l}\text { T2 No, } \\
\text { T1 No }\end{array}$ & $\begin{array}{l}\text { Alive with tumor } \\
\text { recurrence, } 31 \\
\text { mo }\end{array}$ & Yes, Yes \\
\hline 10 & $\begin{array}{l}\text { Adeno- } \\
\text { carcinoma }\end{array}$ & T1 N0 & 17 & Compromised & WWR, stapler & $\begin{array}{c}\text { No (node residue, } \\
\text { noncurative) }\end{array}$ & T1 N2 & $\begin{array}{l}\text { Alive with tumor } \\
\text { recurrence, } 29 \\
\text { mo }\end{array}$ & Yes \\
\hline
\end{tabular}

institute, tumors were resected in keeping with this principle: more than $2 \mathrm{~cm}$ if possible, or at least with a safe margin greater than the lesion diameter under the deflating condition of the lung. ${ }^{1,4,8}$ Because the resected line of limited surgery did not always maintain such a distance, however, for example because of anatomic, physiologic, histopathologic, or technical conditions, we developed a cutting technique with the Nd:YAG laser, if necessary in combination with a stapler. ${ }^{1,4,9,12}$ In addition, conventional frozen-section histologic examination for checking the surgical margin was aggressively performed. However, this intraoperative examination was often not technically complete enough for an accurate diagnosis, for example when a stapler was used, when the cutting surface was too wide, or when the resected specimens were too supple. To address this problem, intraoperative stamped cytologic examination to the surface of surgical margin was introduced, ${ }^{15}$ but the whole area of the resected margin could not be perfectly checked. In contrast, this novel technique of checking for residual tumor cells in the surgical margin offers more advantages. During the operation, the whole area of the margins can be collectively examined. If necessary each margin can be separately tested in a relatively short time, and any aspects of the surgical margin by any dividing method can be examined, whether with open thoracotomy or with VATS. On the basis of this background, we developed this system for limited surgery. ${ }^{10}$ In this study, its surgical results were analyzed on a large scale.

The rate of positive cytologic results in the surgical margin at the attempted limited surgery was unexpectedly high $(11 \%)$, almost the same as preliminarily reported. ${ }^{10}$ However, considering that this rate was closely associated with stage, indication, curability, and tumor size, limited surgery with intentional indication for stage I lung cancer of smaller size has been almost safe in terms of complete resection, suggesting that this test appears unnecessary under such favorable conditions. Nevertheless, in practice it is better to confirm local completeness by this technique intraoperatively, because local failure associated with limited surgery with only an intentional indication may not be 


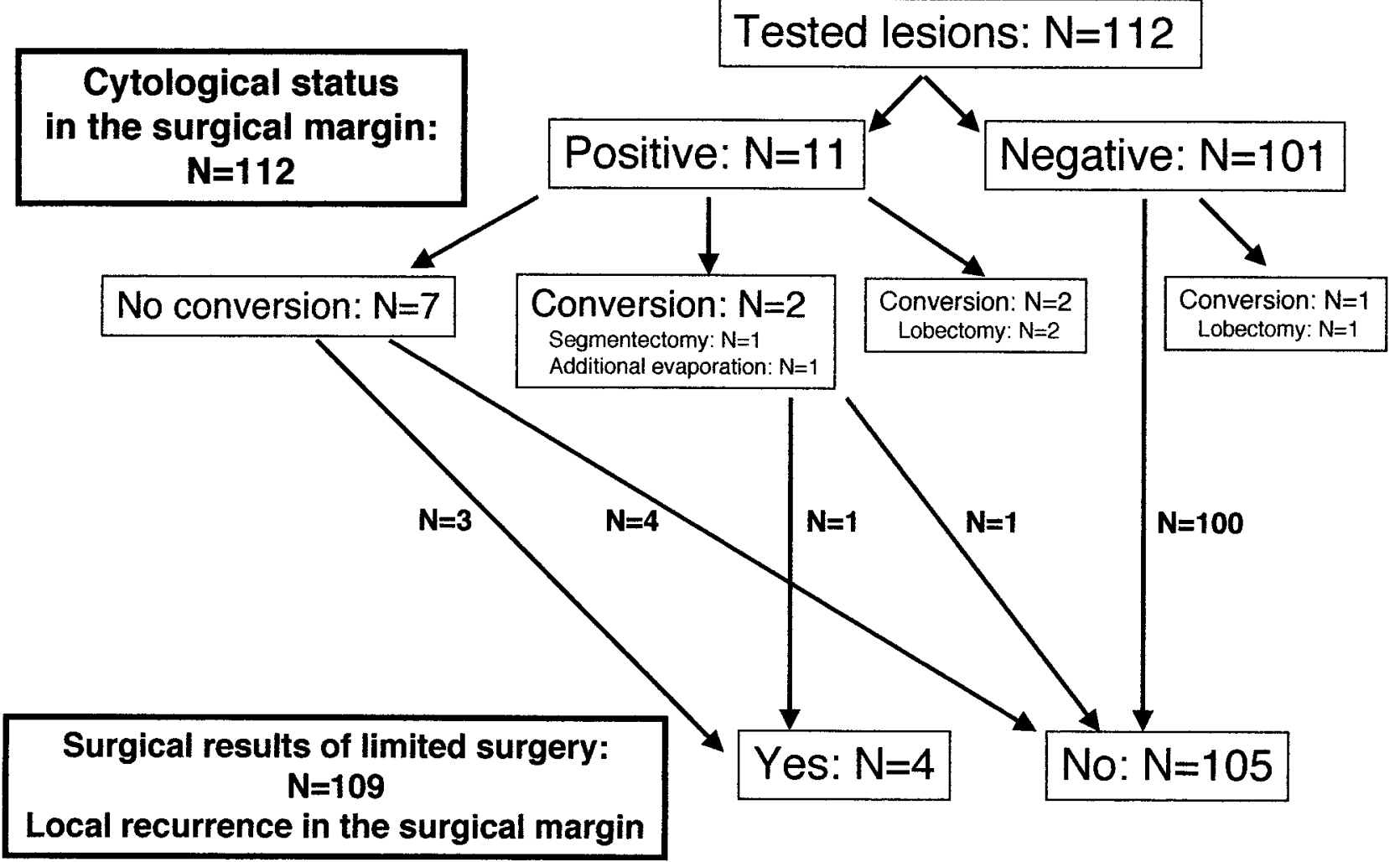

Figure 3. Scheme of surgical results of limited surgery according to cytologic status in surgical margin. There were no local recurrences in surgical margins of lesions with cytologically negative results, whereas there was local recurrence in 4 other lesions, including 3 cytologically positive lesions for which surgical mode was not converted and 1 lesion that was cytologically undetermined after additional evaporation.

permitted. In particular, considering the data by Sawabata and associates, ${ }^{15}$ this technique should be performed especially in cases with a smaller safe margin than $1 \mathrm{~cm}$.

As also was previously reported, ${ }^{10}$ when cytologically positive results in intentional limited surgery are obtained by this technique, the surgical mode should be immediately converted to standard resection. In fact, we have seen only 1 case with such a lesion (lesion 1). Even in such a case of compromised limited surgery, additional resection should be selectively performed if possible. In this series completion segmentectomy was performed for 1 lesion (lesion 3), and completion middle lobe lobectomy was successfully performed for 1 lesion (lesion 2), despite low respiratory function. On the other hand, additional evaporation of the margin with electric scissors or Nd:YAG laser is a modality used as a salvage for potential curability. In fact, we conducted this additional therapeutic modality for 1 lesion (lesion 4), unfortunately with local failure. Recently we reported a case with such a local recurrence after evaporation by Nd:YAG laser in metastasectomy for pulmonary metastasis from colorectal cancer. ${ }^{11}$ At present it is technically impossible to examine tumor residue in the final surgical margin after the evaporation. Thus this technique must be improved in the future.

To date a total of 4 lesions in this series, including 3 with cytologically tumor-positive status and 1 with unknown status in the surgical margin, have shown recurrence at the surgical margin. In contrast, there have been no local recurrences in the surgical margin in cytologically tumor-negative lesions. Thus cytologically negative results by this lavage cytologic technique may yield promising information for complete local curability with limited surgery for lung cancer. Similar data were also obtained for metastasectomy for pulmonary metastases from various organs. ${ }^{11}$ Even if a tumor has such unfavorable factors as deep-seated location and poorly defined tumor margin, we may be encouraged to more completely attempt limited surgery with this checking test.

In the previous series of limited surgery with 63 lung cancer lesions between January 1985 and September 1996, we reported that 1 patient (2\%) undergoing compromised limited surgery had recurrence in the surgical margin. ${ }^{4}$ Among 33 patients undergoing limited surgery between October 1996 and November 1997, we saw such local 
failure in 2 cases, 1 each in the intentional and compromised indication groups, with the rate as great as 6\% (data not shown). Surprisingly, Yano and associates ${ }^{2}$ reported that recurrence in the surgical margin occurred at a rate of $24 \%$ among compromised patients undergoing limited surgery. In addition, although various types of locoregional recurrence were collectively analyzed, rates were $9.5 \%,{ }^{16} 17 \%,{ }^{17}$ and $23 \% 18$ among the patients undergoing intentional limited surgery. In this series among 112 lesions after this novel checking system, 4 lesions recurred in the surgical margin, for a rate of about $4 \%$. The rate dropped to zero $(0 \%)$ when limited to intentionally indicated lesions, and importantly was also zero for finally cytologically negative confirmed lesions. Among the 105 potentially curatively resected lesions, only 1 lesion (1\%) showed local recurrence. Thus, along with the recent increasing chance of limited surgery, local curability has been more complete.

This intraoperative lavage cytologic technique is a promising tool for predicting local recurrence in the surgical margin area of limited surgery for lung cancer. In promoting limited surgery for lung cancer, it is necessary to examine whether the tumor remains by using this technique for checking the surgical margin status. Cytologically negative results in the surgical margin may be a promising indicator against local failure. When a cytologically positive result is obtained, the surgical mode should be changed if possible.

We thank Jun-ichi Ashimura, CT, Sachiko Nagumo, CT, and Yasuyoshi Naruse, CT, for their technical assistance in performing cytologic analyses.

\section{References}

1. Kodama K, Doi O, Yasuda T, Higashiyama M, Yokouchi H. Radical laser segmentectomy for T1 N0 lung cancer. Ann Thorac Surg. 1992; 54:1193-5.

2. Yano T, Yokoyama H, Yoshino I, Tayama K, Asoh H, Hata K, et al. Results of a limited resection for compromised or poor-risk patients with clinical stage I non-small cell carcinoma of the lung. J Am Coll Surg. 1995;181:33-7.

3. Martini N, Bains MS, Burt ME, Zakowski MF, McCormack P, Rusch $\mathrm{VW}$, et al. Incidence of local recurrence and second primary tumors in resected stage I lung cancer. J Thorac Cardiovasc Surg. 1995;109: $120-9$.

4. Kodama K, Doi O, Higashiyama M, Yokouchi H. Intentional limited resection for selected patients with T1 N0 M0 non-small-cell lung cancer: a single-institute study. J Thorac Cardiovasc Surg. 1997;114: 347-53.

5. Lacasse Y, Bucher HC, Wong E, Griffith L, Walter S, Ginsberg RJ, et al. Incomplete resection in non-small cell lung cancer: need for a new definition. Canadian Lung Oncology Group. Ann Thorac Surg. 1998; 65:220-6.

6. Tsubota N, Ayabe K, Doi O, Mori T, Namikawa S, Taki T, et al. Ongoing prospective study of segmentectomy for small lung tumors. Study Group of Extended Segmentectomy for Small Lung Tumor. Ann Thorac Surg. 1999;67:1787-90.

7. Okada M, Yoshikawa K, Hatta T, Tsubota N. Is segmentectomy with lymph node assessment an alternative to lobectomy for non-small cell lung cancer of $2 \mathrm{~cm}$ or smaller? Ann Thorac Surg. 2001;71:956-60.

8. Kodama K, Higashiyama M, Yokouchi H, Takami K, Kuriyama K, Kusunoki Y, et al. Natural history of pure ground-glass opacity after long-term follow-up of more than two years. Ann Thorac Surg. 2002; 73:386-93.

9. Higashiyama M, Kodama K, Yokouchi H, Takami K, Mano M, Kido $\mathrm{S}$, et al. Prognostic value of bronchiolo-alveolar carcinoma component of small lung adenocarcinoma. Ann Thorac Surg. 1999;68:2069-73.

10. Higashiyama M, Kodama K, Yokouchi H, Takami K, Nakayama T, Horai T. A novel test of the surgical margin in patients with lung cancer undergoing limited surgery: Lavage cytologic technique. J Thorac Cardiovasc Surg. 2000;120:412-3.

11. Higashiyama M, Kodama K, Takami K, Higaki N, Yokouchi H, Nakayama T, et al. Intraoperative lavage cytologic analysis of surgical margins as a predictor of local recurrence in pulmonary metastasectomy. Arch Surg. 2002;137:469-74.

12. Kodama K, Doi O, Higashiyama M, Tatsuta M, Iwanaga T. Surgical management of lung metastases: usefulness of resection with the neodymium:yttrium-aluminum-garnet laser with median sternotomy. J Thorac Cardiovasc Surg. 1991;101:901-8.

13. Higashiyama M, Doi O, Kodama K, Yokouchi H, Tateishi R, Horai T, et al. Pleural lavage cytology immediately after thoracotomy and before closure of the thoracic cavity for lung cancer without pleural effusion and dissemination: clinicopathological and prognostic analysis. Ann Surg Oncol. 1997;4:409-15.

14. Kodama K, Higashiyama M, Yokouchi H, Takami K, Kuriyama K, Mano M, et al. Prognostic value of ground-glass opacity found in small lung adenocarcinoma on high-resolution CT scanning. Lung Cancer. 2001;33:17-25.

15. Sawabata N, Mori T, Iuchi K, Maeda H, Ohta M, Kuwahara O. Cytologic examination of surgical margin of excised malignant pulmonary tumor: methods and early results. J Thorac Cardiovasc Surg. 1999;117:618-9.

16. Jensik RJ. The extent of resection for localized lung cancer: segmental resection. In: Kittle $\mathrm{CF}$, editor. Current controversies in thoracic surgery. Philadelphia: WB Saunders; 1986. p. 175-82.

17. Warren WH, Faber LP. Segmentectomy versus lobectomy in patients with stage I pulmonary carcinoma. J Thorac Cardiovasc Surg. 1994; 107:1087-94.

18. Ginsberg RJ, Rubinstein LV. Randomized trial of lobectomy versus limited resection for T1 N0 non-small cell lung cancer. Lung Cancer Study Group. Ann Thorac Surg. 1995;60:615-23.

\section{Authoritative}

The Journal of Thoracic and Cardiovascular Surgery is the most frequently cited thoracic/cardiovascular surgery journal in the Science Citation Index. An article in JTCVS is cited on average almost twice as often as those in the closest cardiothoracic journal. 